\title{
Allergic contact dermatitis pattern in Kuwait: nickel leads the pack. In-depth analysis of nickel allergy based on the results from a large prospective patch test series report
}

\author{
Nawaf Almutairi ${ }^{1,2}$, Fahad Almutawa ${ }^{1,2}$ \\ 1Department of Medicine, Faculty of Medicine, Kuwait University, Kuwait \\ ${ }^{2}$ Department of Dermatology, Farwaniya Hospital, Kuwait
}

Adv Dermatol Allergol 2017; XXXIV (3): 207-215

DOI: https://doi.org/10.5114/ada.2017.67843

\begin{abstract}
Introduction: Contact dermatitis is a relatively common dermatosis reported among several population groups from all around the globe. However, the data from Kuwait is unavailable. Patch tests are essential for the diagnosis of contact sensitization.

Aim: To determine a relative frequency and pattern of sensitizers to different allergens in patients of suspected contact dermatitis in Kuwait and, also to study the role of the commonest sensitizer in detail.

Material and methods: Patch tests were performed in 2461 consecutive patients with a clinical diagnosis of contact dermatitis seen at our hospital between September 1, 2014 and August 31, 2015. Out of the total of 1381 (56.1\%) patients with positive patch test results to at least one allergen, $546(22.2 \%)$ patients with a single positive reaction to nickel only (single largest sensitizer) were selected as the study population for further detailed analysis.

Results: At least one positive patch test reaction was found in 1381 (56.12\%) patients. Nickel was found to be the most common sensitizer seen in $546(40 \%)$ patients. The mean age was $37.3 \pm 13.8$ years and the mean duration of disease was $27.3 \pm 13.8$ months. Most (387/546) patients sensitized were females. The forearms/hands and wrists were the most prevalent sites (52.56\% of the participants). In $58.91 \%$ of women, dermatitis was more often confined to other sites, mostly ears and the neck due to earrings and necklaces. Just more than half of the number (51.09\%) of nickel allergic patients were found in the age group of 15-25 years. Hairdressers/beauticians were the most affected group followed by house workers (housewives, cleaners, housekeepers).

Conclusions: Nickel is the single most common sensitizer found in our patients, and female sex, young age, occupation with long hours of contact to nickel are high risk factors. We recommend that a directive, which limits the release of nickel from products with extended skin contact, be approved in Kuwait.
\end{abstract}

Key words: nickel allergy, patch tests, contact dermatitis.

\section{Introduction}

Allergic contact dermatitis (ACD) is a relatively common dermatosis, classically described as a type IV (delayed type) hypersensitivity response to an exogenous allergen. It may present acutely as an initial sensitization after exposure to the allergen or may be seen in a previously sensitized individual on re-exposure. The epidemiology of contact dermatitis has been analyzed in various studies done in the past from almost all over the world [1-4], but no such data from Kuwait exists. Nickel is the most common identified allergen worldwide, and is extensively used in everyday life. Frequency of nickel allergy is reported to be continuously increasing in several countries, and represents a major health and socioeconomic problem [5]. Hypersensitivity to nickel is found in 13\% of adults and $8 \%$ of children [6].

Dermatitis due to contact with nickel was initially described among workers in the nickel-plating industry and was documented as an allergic response in 1925 [7, 8]. Nickel allergy is a chronic and recurring skin problem. Nickel has frequently been pointed out as a sensitizer capable of triggering both short- and long-lasting sensitivity reactions. An augmented risk of nickel sensitization could possibly be due to wearing nickel-containing jewelry at an early age [9].

Address for correspondence: Prof. Nawaf Almutairi, P.O. Box 280, Farwaniya, 80000, Kuwait, phone: 00965-99370203, fax: 00965-24808167, e-mail: nalmut@usa.net Received: 6.01.2016, accepted: 10.04.2016. 
Females are affected more commonly than males. Nickel allergy may develop at any age. Once developed, it tends to persist for the rest of life [10]. Allergic nickel dermatitis is also a significant occupational problem as work tools and ingredients may release nickel in abundant amounts leading to occupational exposure in industries [11, 12].

Allergy to nickel can manifest in a variety of ways and can result in both cutaneous and systemic manifestations, which range from mild to severe symptoms. A severe form of this allergy is the systemic nickel allergy syndrome, clinically characterized by cutaneous manifestations (contact dermatitis, pompholyx, hand dermatitis dyshidrosis, urticaria) with a chronic course and systemic symptoms (headache, asthenia, itching, and gastrointestinal disorders related to histopathological alterations of gastrointestinal mucosa, borderline with celiac disease) [13].

Nickel is a silvery-white ubiquitous element that can be found in nature. It is usually mixed with other metals to produce alloys. In fact, nickel is contained in various objects and food; it occurs in igneous rocks, as a free metal and together with iron, but it is also a component of living organisms, vegetables etc. [14].

Different types of consumer items, such as jewelry, buttons, and spectacle frames that are in repeated or prolonged contact with the skin, have for many decades been important sources of sensitization to nickel and elicitation of nickel dermatitis. Other sources of consumer and occupational exposure to nickel are also important. Thirty to forty per cent of nickel-sensitive people develop hand eczema, which may become recurrent or chronic, affecting their ability to work and causing large expenses for the society [15]. The individual clinical relevance of nickel allergy can easily be identified but it can be difficult to assess if nickel allergy is acquired privately or occupationally [16].

With increased awareness about nickel allergy, manufacturers tend to use lower nickel-releasing materials for their products but still some amount of exposure may occur.

Exposure to nickel ions through inhalation and oral exposure has not been shown to produce nickel-sensitization in non-nickel-sensitized individuals. Rather, oral exposure in some patients has been verified to lessen susceptibility or lead to immune tolerance to dermal nickel sensitization [17].

Allergic contact dermatitis to nickel requires the activation of antigen-specific acquired immunity leading to the development of effector T cells, which mediate the skin inflammation. The ACD is a T-cell-mediated inflammatory reaction occurring at the site of challenge with a contact allergen in sensitized individuals. It is characterized by redness, papules and vesicles, followed by scaling and dry skin [18].

\section{Aim}

The aim of this study was to determine the relative frequency and pattern of sensitizers to different allergens in patients of suspected contact dermatitis in Kuwait, and to analyze in detail the commonest sensitizer found in the study.

\section{Material and methods}

This study was conducted in the dermatology departments of two tertiary level government hospitals, in two different governorates in Kuwait. Patients clinically diagnosed with contact dermatitis attending the outpatient clinic of our department from September 1, 2014 to August 31, 2015 were enrolled in the study. The study was approved by our hospital ethics committee. The inclusion criteria included patients of suspected contact dermatitis, 10-75 years of age, willingness to undergo patch tests after giving informed consent. Exclusion criteria were patients suffering from renal, hepatic, and cardiovascular diseases, or co-existing, uncontrolled hypertension and diabetes mellitus. Cases with any kind of food sensitivity or any other confirmed skin diseases triggering acute onset of skin rash were also excluded.

A detailed comprehensive history and physical examination regarding demographic characteristics, age, sex, occupation as a possibility for occupational dermatitis, clinical features, location and duration of dermatitis, family/past history of atopic dermatitis, asthma, allergic rhinitis, and possible source of allergens (jewelry, cosmetics, coin handling, occupational exposure etc.) were collected from each patient, and necessary baseline hematological and biochemical tests like complete blood count and general health profile were done. All patients suspected of having contact dermatitis were screened using the FDA-approved ready-to-use Epicutaneous Patch test (TRUE test; Panel 1, 2 \& 3; Smartpractice DK, APS that includes 36 of the most common allergens). An FDAapproved ready-to-use Epicutaneous Patch test (TRUE test); Nickel sulfate hexahydrate (purity $\geq 98.5 \%$ ) is used to formulate this patch. The active allergenic component is nickel. The gel vehicle is hydroxypropyl cellulose. The product is formulated to contain $200 \mu \mathrm{g} / \mathrm{cm}^{2}$ of nickel sulfate hexahydrate, which corresponds to $36 \mu \mathrm{g}$ of nickel per patch. The Patch was applied to the upper back for $48 \mathrm{~h}$ and read on removal, and then again at $72 \mathrm{~h}$ after removal. Patch test positivity was defined as revealing erythema and/or edema at $72 \mathrm{~h}$ utilizing the standard International Contact Dermatitis Research Group Criteria (ICDRG) [19]. Reactions of $1+, 2+$, or $3+$ grade reading was interpreted as a positive response. An irritant response, a doubtful reading, or a negative reading was interpreted as a negative response.

Clinical significance was defined by corroborating it by a history of contact with any material containing the 
sensitizing agent at the site of the dermatitis, as reported by the patient.

\section{Statistical analysis}

Data analysis was performed using SPSS Version 17.0 (SPSS, Inc., Chicago, IL, USA). Absolute and relative frequencies were calculated for qualitative variables, and mean (SD) for quantitative variables. The $\chi^{2}$ test was used to test the significance of the role of sex. Regression analysis was performed to test the correlation of age. A $p$-value of $<0.05$ was considered as statistically significant.

\section{Results}

Out of the 2985 patients (1642 males and 1343 females) with suspected contact dermatitis seen during the study period, 2461 patients fulfilled the study requirements, and could be available for final analysis of the patch test results. Five hundred and twenty four patients could not be included for the following reasons: 484 patients due to associated systemic illness; 27 patients did not complete 2 readings of patch tests, and 13 patients refused to give consent to undergo patch testing. Out of the total 2461 patients analyzed, there were 1331 (54.08\%) men and 1130 (45.92\%) women, of these 1381 (56.12\%) patients had positive patch test results to at least one allergen. The details of the positive patch test reaction are given in Table 1. Nickel was found to be the most common sensitizer seen in our patients, and in 546 patients (387 females, 159 males; females : males ratio $2.4: 1$ ), nickel was the sole (isolated) sensitizing agent, which constituted about $40 \%$ of the total patients with positive patch test results.

These 546 isolated nickel patch test positive patients were studied in detail for their demographic characteristics, associated risk factors, and disease history and pattern to extract meaningful data, and probe positive causative association for their disease.

The mean age was $37.3 \pm 13.8$ years with a range from 10 to 75 years. Men were slightly older than women (Table 2). The mean duration of the disease was $27.3 \pm 13.8$ months, ranging from 2 to 65 months. The majority of the patients had the disease for 3 to 12 months (41.39\%). Thirty-two (5.86\%) patients had a personal history of one or more types of atopy (asthma, 9; hay fever, 7; atopic dermatitis, 16). The incidence of personal and family atopy and sensitization to nickel was greater in women than in men.

The forearms/hands and wrists were the most prevalent sites (52.56\% of the participants). In the male population, the symptoms and/or signs of dermatitis were more commonly localized on the hands, and in some patients restricted to the fingertips, and the ring fingers. Wrist dermatitis was due to arm rings and wristwatch shells, their metallic bracelets, or watch band clasps. In women, dermatitis was more often confined to other sites mostly the ears and neck due to earrings and necklaces (58.91\%). Sub-umbilical dermatitis (17.77\%) was mostly induced by jeans buttons and belt buckles.

Nearly half (48.17\%) of the patients showed erythematous rash, followed by chronic eruption in $33.33 \%$, vesicular eruption in $25.09 \%$, and lastly pustular eruption in $11.05 \%$ (Table 2).

The maximum number of nickel allergic patients was found in the age group of $15-25$ years (51.09\%) followed by the age group of 26-35 years. Females were more prevalent in all the age groups except for the 46-55 age group (Table 3). A comparison of women in the age group of 15-23 years with women in older age groups showed a statistically significant difference $(p<0.02)$.

Table 4 reports the occupations of patients in the study population by sex. Hairdressers/beauticians were the most affected group followed by house workers (housewives, cleaners, housekeepers).

Amongst nickel-allergic patients, nearly all sorts of metal objects were reported as a cause of nickel dermatitis. Assumed sources of nickel leading dermatitis, as informed by the nickel-positive patients, are shown in Table 5. Earrings, ear lobe decorations, wristwatches, jeans buttons and metal frames of spectacles were the items most commonly described as items that caused nickel dermatitis.

The degree of patch test reactivity to isolated nickel hypersensitivity is shown in Table 6. Most of the cases (61.54\%) had 1+ degree of reaction. The most severe reaction recorded (grade $3+$ ) was most prevalent in females with hand dermatitis.

\section{Discussion}

Contact dermatitis to nickel represents a significant morbidity that can lead to inability to work, a decreased quality of life, and noteworthy healthcare expenses.

Nickel was the most common positive patch test allergen in all patch tested patients (23.9\%) in this study. As the patch test measures only the sensitivity status of the individual, a positive test reaction is not certainly an indicator of clinical disease, so the clinical examination and history of metal sensitization were corroborated with patch test results in each of these patients. The reason for the relatively high prevalence of nickel ACD could be the use of nickel in consumer items that come in direct and prolonged contact with the skin. For example nickel metal in plated articles or some alloys (e.g., jewelry, watches, and eyeglasses). However, exposure may also occur in certain occupational settings generally associated with soluble nickel salts.

In 2004, the ESSCA working group collected data from 31 dermatology departments in eleven European countries (Austria, Denmark, Germany, Italy, Lithuania, 
Table 1. Details of the pattern of positive patch test results in both genders with positive relevance of each metal sensitizer

\begin{tabular}{|c|c|c|c|c|}
\hline Standard patch test series allergens & $\begin{array}{c}\text { Males }(N=1331) \\
n(\%)\end{array}$ & $\begin{array}{c}\text { Females }(N=1130) \\
n(\%)\end{array}$ & $\begin{array}{c}\text { Positive results } \\
n(\%)\end{array}$ & $\begin{array}{c}\text { Positive relevance } \\
n(\%)\end{array}$ \\
\hline Nickel sulfate & $176(13.2)$ & $413(36.5)$ & $589(23.9)$ & $524(89)$ \\
\hline Wool alcohols (Lanolin) & $15(1.1)$ & $17(1.5)$ & $32(1.3)$ & \\
\hline Neomycin sulfate & $7(0.5)$ & $12(1)$ & $19(0.8)$ & \\
\hline Potassium dichromate & $102(7.7)$ & $53(4.7)$ & $155(6.3)$ & $135(87)$ \\
\hline Caine mix & $0(0)$ & $1(0.1)$ & $1(0.04)$ & \\
\hline Fragrance mix & $74(5.5)$ & $69(6.1)$ & $143(5.8)$ & \\
\hline Colophony & $31(2.3)$ & $5(0.4)$ & $36(1.5)$ & \\
\hline Paraben mix & $4(0.3)$ & $3(0.3)$ & $7(0.3)$ & \\
\hline Negative control & $0(0)$ & $0(0)$ & $0(0)$ & \\
\hline Balsam of Peru & $67(5)$ & $51(4.5)$ & $118(4.8)$ & \\
\hline Ethylenediamine dihydrochloride & $8(0.6)$ & $6(0.5)$ & $14(0.6)$ & \\
\hline Cobalt dichloride & $89(7.9)$ & $135(12)$ & $224(9.1)$ & $179(80)$ \\
\hline$P$-tert-butylphenol formaldehyde resin & $29(2.2)$ & $21(1.8)$ & $50(2)$ & \\
\hline Epoxy resin & $11(0.8)$ & $5(0.4)$ & $16(0.6)$ & \\
\hline Carba mix & $12(0.9)$ & $7(0.6)$ & $19(0.8)$ & \\
\hline Black rubber mix & $27(2)$ & $11(1)$ & $38(1.5)$ & \\
\hline $\mathrm{Cl}^{+} \mathrm{Me}$ - isothiazolinone & $7(0.5)$ & $6(0.5)$ & $13(0.5)$ & \\
\hline Quaternium-15 & $8(0.6)$ & $3(0.3)$ & $11(0.4)$ & \\
\hline Methyldibromo glutaronitrile & $0(0)$ & $0(0)$ & $0(0)$ & \\
\hline$P$-Phenylenediamine & $129(9.7)$ & $56(5)$ & $185(7.5)$ & \\
\hline Formaldehyde & $26(2)$ & $20(1.7)$ & $46(1.9)$ & \\
\hline Mercapto mix & $10(0.7)$ & $6(0.5)$ & $16(0.6)$ & \\
\hline Thimerosal & $26(2)$ & $21(1.8)$ & $47(1.9)$ & \\
\hline Thiuram mix & $34(2.5)$ & $21(1.8)$ & $55(2.2)$ & \\
\hline Diazolidinyl urea & $2(0.01)$ & $1(0.09)$ & $3(0.1)$ & \\
\hline Quinoline mix & $0(0)$ & $0(0)$ & $0(0)$ & \\
\hline Tixocortol-21-pivalate & $2(0.01)$ & $3(0.3)$ & $5(0.2)$ & \\
\hline Gold sodium thiosulfate & $6(0.4)$ & $11(1)$ & $17(0.7)$ & $11(65 \%)$ \\
\hline Imidazolidinyl urea & $3(0.2)$ & $3(0.3)$ & $6(0.2)$ & \\
\hline Budesonide & $6(0.4)$ & $5(0.4)$ & $11(0.4)$ & \\
\hline Hydrocortisone-17-butyrate & $2(0.01)$ & $3(0.3)$ & $5(0.2)$ & \\
\hline Mercaptobenzothiazole & $3(0.2)$ & $9(0.8)$ & $12(0.5)$ & \\
\hline Bacitracin & $0(0)$ & $0(0)$ & $0(0)$ & \\
\hline Parthenolide & $0(0)$ & $0(0)$ & $0(0)$ & \\
\hline Disperse blue 106 & $0(0)$ & $0(0)$ & $0(0)$ & \\
\hline 2-Bromo-2-nitropropane-1,3-diol & $12(0.9)$ & $6(0.5)$ & $18(0.7)$ & \\
\hline
\end{tabular}


Table 2. Characteristics of the cases showing positive patch test results only to nickel

\begin{tabular}{|c|c|c|c|}
\hline Variable & Female $(N=387)$ & Male $(N=159)$ & Total $(N=546)$ \\
\hline$\%$ of nickel sensitization to total patch test positive patients $(N=2461)$ & 15.73 & 6.46 & 22.19 \\
\hline Age [years], median (range) & $37(10-68)$ & $41(17-75)$ & $37(10-75)$ \\
\hline Personal atopy, $n(\%)$ & $24(6.20)$ & $8(5.03)$ & $32(5.86)$ \\
\hline \multicolumn{4}{|l|}{ Duration of disease [months], $n(\%):$} \\
\hline $1-6$ & $65(16.79)$ & $31(19.50)$ & $96(17.58)$ \\
\hline $7-12$ & $167(43.15)$ & $59(37.11)$ & $226(41.39)$ \\
\hline $13-24$ & $78(20.16)$ & $25(15.72)$ & $103(18.86)$ \\
\hline$>24$ & $97(25.06)$ & $37(23.27)$ & $134(24.54)$ \\
\hline \multicolumn{4}{|l|}{ Morphological forms of the lesions, $n(\%)$ : } \\
\hline Erythematous eruption & $186(48.06)$ & $77(48.43)$ & $263(48.17)$ \\
\hline Vesicular eruption & $88(22.74)$ & $49(30.82)$ & $137(25.09)$ \\
\hline Pustular eruption & $45(11.63)$ & $20(12.58)$ & $65(11.05)$ \\
\hline Chronic eruption & $71(18.35)$ & $111(69.81)$ & $182(33.33)$ \\
\hline \multicolumn{4}{|l|}{ Distribution of lesions, $n(\%)$ : } \\
\hline Scalp & $66(17.05)$ & $21(13.21)$ & $87(15.93)$ \\
\hline Face & $101(26.10)$ & $49(30.82)$ & $150(27.47)$ \\
\hline Ear and neck & $228(58.91)$ & $11(6.92)$ & $239(43.77)$ \\
\hline Forearms/hands/wrists & $176(45.48)$ & $111(69.81)$ & $287(52.56)$ \\
\hline Abdomen/back & $43(11.11)$ & $20(12.58)$ & $63(11.54)$ \\
\hline Sub-umbilical & $64(16.54)$ & $33(20.75)$ & $97(17.77)$ \\
\hline Lower limbs/feet & $66(17.05)$ & $42(26.42)$ & $108(19.78)$ \\
\hline Other sites & $78(20.16)$ & $34(21.38)$ & $112(20.51)$ \\
\hline
\end{tabular}

Table 3. Extent of the nickel allergy according to age groups

\begin{tabular}{lccc}
\hline Age [years] & Female $(N=387)$ & Male $(N=159)$ & Total $(N=546)$ \\
$n(\%)$
\end{tabular}

Poland, Spain, Switzerland, Sweden, the Netherlands and United Kingdom) and reported positive responses to nickel in the $20.1 \%$ of the 10,000 patch tested subjects. In the ESSCA study, nickel ranked the first among the allergens, the lowest percentage of nickel allergy being found in Denmark (9.7\%) and the highest in Italy (32.2\%) [20].
Our study confirms that the incidence of nickel sensitization is noticeably different amongst the two sexes: $15.73 \%$ of females versus $6.46 \%$ of males were found to be sensitized to nickel. Studies on the prevalence of nickel sensitivity generally show that in the general population, up to $17 \%$ of women and $3 \%$ of men are nickel 
Table 4. Relation between nickel contact dermatitis, sex and occupation

\begin{tabular}{lccc}
\hline Occupation & $\begin{array}{c}\text { Female } \\
n(\%)\end{array}$ & $\begin{array}{c}\text { Male } \\
n(\%)\end{array}$ & $\begin{array}{c}\text { Total } \\
n(\%)\end{array}$ \\
\hline Hairdressers/beauticians & $93(24.03)$ & $32(20.13)$ & $125(22.90)$ \\
\hline Caterers & $2(0.52)$ & $9(5.66)$ & $11(2.15)$ \\
\hline House workers & $68(17.57)$ & $10(6.29)$ & $78(14.29)$ \\
\hline Cashiers/coin handlers & $31(8.01)$ & $24(15.09)$ & $55(10.07)$ \\
\hline Metal workers & $1(0.26)$ & $33(20.75)$ & $34(6.23)$ \\
\hline Medical/dental staff & $37(9.56)$ & $9(5.66)$ & $46(8.42)$ \\
\hline Office staff & $55(14.21)$ & $14(8.81)$ & $69(12.64)$ \\
\hline Sales assistants & $13(3.36)$ & $5(3.14)$ & $18(3.30)$ \\
\hline Students & $54(13.95)$ & $17(10.69)$ & $71(13.00)$ \\
\hline Non specified/unknown & $33(8.53)$ & $6(3.77)$ & $39(7.14)$ \\
\hline Total & $387(100.00)$ & $159(100.00)$ & $546(100.00)$ \\
\hline
\end{tabular}

Table 5. Alleged sources of nickel leading to dermatitis seen in our patients

\begin{tabular}{lccc}
\hline Type of object & Female $(\boldsymbol{N}=387)$ & Male $(\boldsymbol{N}=159)$ & Total $(\boldsymbol{N}=546)$ \\
$n(\%)$
\end{tabular}

Table 6. Frequency and degree of patch test reactivity for isolated nickel hypersensitivity in both sexes

\begin{tabular}{lcccc}
\hline Gender & $\begin{array}{c}\text { Positive }+1 \mathrm{~N} \\
n(\%)\end{array}$ & $\begin{array}{c}\text { Positive +2N } \\
n(\%)\end{array}$ & $\begin{array}{c}\text { Positive +3N } \\
n(\%)\end{array}$ & $\begin{array}{c}\text { Total } \\
n(\%)\end{array}$ \\
\hline Female & $209(54.01)$ & $60(15.50)$ & $118(30.49)$ & $387(100.00)$ \\
\hline Male & $124(77.99)$ & $9(5.66)$ & $26(16.35)$ & $159(100.00)$ \\
\hline Total & $336(61.54)$ & $69(12.64)$ & $141(25.82)$ & $546(100.00)$ \\
\hline
\end{tabular}

sensitive [21] thus concerning the prevalence of sensitization and sex, the results are consistent with those of previous reports [22-24].

This remarkable difference in prevalence between females and males may be associated with the considerably higher prevalence of ear piercing amongst women. However, other causes such as hormonal differences and the tendency for females to wear more artificial jewelry than males may also play a role [25]. In Denmark, after introducing a ban on earrings with high nickel content, the risk of nickel allergy in girls wearing earrings dropped by $64 \%$ [26], which favors the view that sex differences in the prevalence of sensitization to nickel reflect differences in exposure.

As regards the distribution of lesions in the contact dermatitis patients, the data obtained match those of a previous study in this population [27], in which the most common locations were also the hands, upper limbs and face including ears and the neck. The forearms/hands and wrists being the most prevalent site (52.56\% of the participants) and hand eczema prevailed among men more than in females. There are various 
mechanisms that can exacerbate and exaggerate hand eczema among nickel-sensitized individuals [15]. Pressure, sweat, moisture, and friction may increase the severity of nickel hypersensitivity. Occupational exposure to sufficient concentrations of nickel induces and provokes hand contact dermatitis [11, 16].

In women, dermatitis was more often confined to other sites mostly the ears and neck due to earrings and necklaces (58.91\%). Sub-umbilical dermatitis (17.77\%) mostly induced by jeans buttons and belt buckles. Todd et al. [28] found that 77 (31.2\%) of 247 patients with pierced ears were allergic to nickel compared to only $3(6.4 \%)$ patients without pierced ears $(p=0.001)$, which confirms earlier suggestions that nickel allergy (as assessed by patch testing) is promoted by ear piercing. Tools used for cosmetic in the face (e.g., eyelash curlers, hairdressing scissors, hair curlers, and eye shadow and makeup applicators) may also be sources of nickel allergy [29].

Regarding age, all age ranges were represented, with $51.09 \%$ of patients in the $15-25$ year-old age group, followed by the 26-35 year-old age (19.23\%), corresponding to the most active sector of the population in Kuwait, which is therefore the segment most exposed to sensitization. The highest incidence and prevalence of nickel ACD has been noted by the North American Contact Dermatitis Group in the age group of 10 to 19 years [30]. Dawn et al. [31] also noted similar results, with most of their patients being in the 11-20 year age group in 1982 and 21-30 year age group.

Nickel sensitization seemed to decline in the older ages (> 45 years); and this finding is observed by other researchers $[32,33]$. Based on their results; the prevalence of nickel allergy was most possibly decreasing with the increasing age, possibly because of a reduction in contact to imitation jewelry as well as different incidences of ear piercing in different generations.

Atopy was observed in only $5.86 \%$ of our patients. The association between atopic dermatitis and ACD has long been a debated issue. The influence of atopy on susceptibility to nickel sensitization and to contact dermatitis in general remains uncertain. Many authors proposed the presence of atopy as either a risk factor or a protecting factor [34]. Some authors [35, 36] have found a higher prevalence of ACD in atopic patients, while other authors [37, 38] have claimed that cell-mediated immunity is suppressed in atopic dermatitis with an associated reduced capability to experience contact allergy. Allergic contact dermatitis is a T-cell mediated skin inflammation caused by recurrent skin interaction to contact allergens. In atopic dermatitis, a mixture of both $\mathrm{Th}_{2}$ and $\mathrm{Th}_{1} \mathrm{Oc}-$ curs and the interactions between them account for the clinical characteristics of the disease. Quantitative balance between $T h_{1}$ and $T h_{2}$ reactions along a time axis is very important to predict whether the cytokine pattern of atopic dermatitis patients favors or inhibits the development of ACD [39].
The individual clinical relevance of nickel allergy can easily be identified but it can be difficult to assess if nickel allergy was acquired privately or occupationally [16]. Hairdressers/beauticians were the most affected group followed by house workers (housewives, cleaners, housekeepers) in our series of patients. Shah et al. [40] noted that hairdressing was one of the most common occupations in their patients with nickel dermatitis. However, by and large most authors agree that female hairdressers are sensitized by ear piercing rather than by occupational exposure to nickel [41]. Secondary contact sensitivity to nickel is probably of importance in the hairdresser's hand dermatitis. When nickel allergic hairdressers present with hand eczema, their work tools like scissors and crochet hooks should be investigated for nickel release [42].

A related problem occurs in cleaners and caterers as nickel allergy is frequent and usually precedes employment in the field [43].

Regarding patch test reactivity, most of the patients $(61.54 \%)$ had $1+$ degree of reaction, while +3 reaction followed it, and $2+$ degree of reaction was the least. Thyssen et al. [44] evaluated whether regulatory interventions on nickel and chromate exposure have reduced the proportion of strong patch test reactions. They found that the proportion of $3+$ reactions to nickel sulfate was reduced and almost disappeared after the mid- and late 1980s, and that $1+$ and $2+$ nickel reactions are equally frequent. The difference in results may be that there are no such regulatory interventions in Kuwait.

The EU recognized the possibility to regulate the presence of $\mathrm{Ni}$ in metallic objects intended for the contact with the human skin. Due to the significance of dangers and the large costs and suffering related to nickel allergy, nickel has been regulated and announced in the European Union (EU) for prevention of nickel allergy and eczema. The Nickel Directive was approved by the European Parliament and Council in 1994 [45]. When the EU Nickel Directive was drafted, precise items such as earrings, bracelets and other types of jewelry to be worn in prolonged contact with the skin were listed as those for which control was compulsory. The regulation presented a maximum release of nickel of $0.5 \mu \mathrm{g} / \mathrm{cm}^{2}$ per week from items intended to be in direct and prolonged contact with the skin, and a maximum release of nickel of $0.2 \mu \mathrm{g} / \mathrm{cm}^{2}$ per week from piercing earrings [46].

Even though the EU has banned the use of $\mathrm{Ni}$ and $\mathrm{Ni}$ salts in cosmetic products, cases of skin contact with $\mathrm{Ni}$ from cosmetics do exist in eye shadows [47], henna tattoo mixtures [48] and body creams [49] sold as "nickel-tested".

Nickel dermal sensitization depends on a corrosion process. Several factors are necessary for an allergic reaction to occur, which includes the dose of nickel, surface area in contact between the metal and the skin, its reaction with sweat and individual susceptibility [50]. Heat, humidity, and increased sweat promote the speed with which nickel ions are presented to the skin [51]. 
The development of nickel ACD necessitates that a person becomes immunologically sensitized to nickel. Nickel can induce an allergic reaction by three different ways [5]:

1) It binds to the carrier protein in the extracellular space and subsequently is processed and presented by an antigen presenting cell (APC) in the context of MHC class II molecule, which activates CD4+ lymphocytes.

2) Nickel penetrates into the cell where it binds to intracellular proteins, and subsequently it is presented in the context of MHC class I molecule, which activates CD8+ lymphocytes,

3) Nickel can "bridge" the MHC molecule together with the TCR receptor on lymphocyte without actually filling the antigen-binding site, which is in analogy to superantigens.

Contact dermatitis is not caused by nickel itself but by the nickel salts which are formed under the influence of perspiration in contact with an item, like jewelry, for a long time. This phenomenon is continuously accompanied by corrosion or rusting of the object. When an allergy to nickel has been developed, it mostly persists for life [52].

There is evidence that skin 'hardening' (suggested loss of reactivity because of constant or intermittent exposure) may prevent nickel dermatitis in some individuals [53] and that immunotolerance is possible. It is notable that the nickel-producing and nickel-using industries in which direct skin contact with various forms of nickel metal and salts is routine workers presenting with symptoms of nickel ACD very rarely have contact with nickel. The fact that this is not seen may be due to tolerance that the workers acquire over time via an alternate route of exposure (inhalation or ingestion), which causes no allergic reaction by the immune system, even when higher nickel exposures are received later. Patients having had oral contact with nickel-releasing appliances (dental braces) at an early age, but only if prior to ear piercing, showed a reduced frequency of nickel hypersensitivity. Oral administration of the antigen before potential sensitization can induce systemic immune tolerance in men. These results support that induction of specific systemic immunologic tolerance by timely oral administration of antigens is feasible in men [54].

\section{Conclusions}

Nickel sensitization is a major community health problem due to the high frequency, and extensive existence of nickel in the daily life. This study does not indicate new sources of nickel allergy, but substantiates already known causes. Female sex, young age, occupation with long hours of contact to nickel are risk factors. The clinical diagnosis of nickel allergy through history taking, medical assessment and patch testing is fairly modest and reliable. Regulation and/or legislation to avoid or decrease nickel contact at a young stage of life would reduce rates of sen- sitization. We recommend that a directive, which limits the maximum permissible release of nickel from products with extended skin contact, dependable on the concentrations assigned in Europe, be approved in Kuwait. Producers and wholesalers should be educated about this rising health problem and counseled to play their role in protecting the health of their clients. Increasing community alertness of the problem and undertaking regulatory actions look to be the solitary available actual method of reducing the prevalence of nickel allergy.

\section{Acknowledgments}

This work was financially supported by a grant from the Kuwait University. Source of funding: KU Grant MM013.

\section{Conflict of interest}

The authors declare no conflict of interest.

\section{References}

1. Bordel-Gomez MT, Romero M, Castrodeza-Sanz J. Epidemiology of contact dermatitis: prevalence of sensitization to different allergen and associated factors. Actas Dermosifiliogr 2010; 101: 59-75.

2. Kuljanac I, Knezevic E, Cvitanovic H. Epicutaneous patch test results in children and adults with allergic contact dermatitis in Karlovac County: a retrospective survey. Actas Dermatovenereol Croat 2011; 19: 91-7.

3. Krecisz B, Chomiczewska D, Palczynski C, Kiec-Swierczynska M. Contact allergy to metals in adolescents. Nickel release from metal accessories 7 years after the implementation of the EU nickel directive in Poland. Contact Dermatitis 2011; 67: 270-6.

4. Bregnbak D, Johansen JD, Jellesen MS, et al. Chromium allergy and dermatitis: prevalence and main findings. Contact Dermatitis 2015; 73: 261-80.

5. Wojciechowska M, Czajkowski R, Kowaliszyn B, et al. Analysis of skin patch test results and metalloproteinase-2 levels in a patient with contact dermatitis. Postep Derm Alergol 2015; 32: 154-61.

6. Czarnobilska E, Obtułowicz K, Wsołek K, et al. [Mechanisms of nickel allergy]. Przegl Lek 2007; 64: 502-5.

7. Namikoshi T, Yoshimatsu T, Suga K, et al. The prevalence of sensitivity to constituents of dental alloys. J Oral Rehabil 1990; 17: 377-81.

8. Counts AL, Miller MA, Khakhria ML, Strange S. Nickel allergy associated with a transpalatal arch appliance. J Orofac Orthop 2002; 63: 509-15.

9. McDonagh AJ, Wright AL, Cork MJ, Gawkrodger DJ. Nickel sensitivity: the influence of ear piercing and atopy. Br J Dermatol 1992; 126: 16-8.

10. Sharma AD. Relationship between nickel allergy and diet. Indian J Dermatol Venereol Leprol 2007; 73: 307-12.

11. Lidén C, Röndell E, Skare L, Nalbanti A. Nickel release from tools on the Swedish market. Contact Dermatitis 1998; 39: 127-31.

12. Thyssen JP, Jensen P, Lidén C, et al. Assessment of nickel and cobalt release from 200 unused hand-held work tools for sale 
in Denmark - sources of occupational metal contact dermatitis? Sci Total Environ 2011; 409: 4663-6.

13. Tammaro A, Narcisi A, Persechino S, et al. Topical and systemic therapies for nickel allergy. Dermatitis 2011; 22: 251-5.

14. Tammaro A, De Marco G, Persechino S, et al. Allergy to nickel: first results on patients administered with an oral hyposensitization therapy. Int I Immunopathol Pharmacol 2009; 22: 837-40.

15. Lidén C, Bruze M, Menné T. Metals. In: Contact Dermatitis. $4^{\text {th }}$ edn. Frosch PJ, Menné T, Lepoittevin JP (eds.). Springer-Verlag, Berlin-Heidelberg 2006; 537-68.

16. Tanko Z, Diepgen TL, Weisshaar E. Is nickel allergy an occupational disease? Discussion of the occupational relevance of a type IV allergy to nickel (II) sulfate using case reports. J Dtsch Dermatol Ges 2008; 6: 346-9.

17. Van Hoogstraten IM, Boden D, von Blomberg ME, et al. Persistent immune tolerance to nickel and chromium by oral administration prior to cutaneous sensitization. J Invest Dermatol 1992; 99: 608-16.

18. Krasteva M, Kehren J, Sayag M, et al. Contact dermatitis II. Clinical aspects and diagnosis. Eur J Dermatol 1999; 9: 144-59.

19. Wahlberg JE. Patch testing. In: Textbook of Contact Dermatitis. $3^{\text {rd }}$ edn. Rycroft RJ, Frosch PJ, Lepoittevin JP (eds.). SpringerVerlag, Berlin 2001; 435-68.

20. The ESSCA Writing Group. The European Surveillance System of Contact Allergies (ESSCA): results of patch testing the standard series, 2004. JEADV 2008; 22: 174-81.

21. Thyssen JP, Menné T. Metal allergy - a review on exposures, penetration, genetics, prevalence, and clinical implications. Chem Res Toxicol 2010; 23: 309-18.

22. Dotterud LK, Smith-Sivertsen T. Allergic contact sensitization in the general adult population: a population-based study from Northern Norway. Contact Dermatitis 2007; 56: 10-5.

23. Machovcova A, Dastychiva E, Kostalova D, et al. Common contact sensitizers in the Czech Republic. Patch test results in 12,058 patients with suspected contact dermatitis. Contact Dermatitis 2005; 53: 162-6.

24. Modjtahedi BS, Modjtahedi SP, Maibach HI. The sex of the individual as a factor in allergic contact dermatitis. Contact Dermatitis 2004; 50: 53-9.

25. Kwangsukstith C, Maibach HI. Effect of age and sex on the induction and elicitation of allergic contact dermatitis. Contact Dermatitis 1995; 33: 289-8.

26. Jensen CS, Lisby S, Baadsgaard O, et al. Decrease in nickel sensitization in a Danish school girl population with ears pierced after implementation of a nickel-exposure regulation. $\mathrm{Br}$ J Dermatol 2002; 146: 636-42.

27. Grupo Brasileiro de Estudo em Dermatite de Contato. Estudo multicentrico para elaboragao de uma bacteria padreo brasileira de testes de contato. An Bras Dermatol 2002; 75: 147-56.

28. Todd DJ, Burrows D. Nickel allergy in relationship to previous oral and cutaneous nickel contact. Ulster Med J 1989; 58: 168-71.

29. Jacob SE, Silverberg JI, Rizk C, Silverberg N. Nickel ferrule applicators: a source of nickel exposure in children. Pediatr Dermatol 2015; 32: e62-3.

30. North American Contact Dermatitis Group. Epidemiology of contact dermatitis in North America. Arch Dermatol 1993; 108: 537-40.

31. Dawn G, Gupta G, Forsyth A. The trend of nickel allergy from a Scottish tertiary referral centre. Contact Dermatitis 2000; 43: 27-30.

32. Hegewald J, Uter W, Pfahlberg A, et al. A multifactorial analysis of concurrent patch test reactions to nickel, cobalt, and chromate. Allergy 2005; 60: 372-8.
33. Akasya-Hillenbrand E, Ozkaya-Bayazit E. Patch test results in 542 patients with suspected contact dermatitis in Turkey. Contact Dermatitis 2002; 46: 17-23.

34. Spiewak R. Atopy and contact hypersensitivity: a reassessment of the relationship using objective measures. Ann Allergy Asthma Immunol 2005; 95: 61-5.

35. Larsson-Stymne B, Widström L. Ear piercing: a cause of nickel allergy in schoolgirls? Contact Dermatitis 1985; 13: 289-93.

36. Dotterud LK, Falk ES. Metal allergy in North Norwegian school children and its relationship with ear piercing and atopy. Contact Dermatitis 1994; 31: 308-13.

37. Leung DYM, Geha RS. Immunoregulatory abnormalities in atopic dermatitis. Clin Rev Allergy 1986; 4: 67-86.

38. Clark RAF. Cell-mediated and IgE-mediated immune responses in atopic dermatitis. Arch Dermatol 1989; 125: 413-6.

39. Jurakić-Tončić R, Lipozenčić J, Martinac I, Gregurić S. Immunology of allergic contact dermatitis. Acta Dermatovenerol Croat 2010; 19: 51-68.

40. Shah M, Lewis FM, Gawkrodger DJ. Nickel as an occupational allergen. Arch Dermatol 1998; 134: 1231-6.

41. Warshaw EM, Wang MZ, Mathias CG, et al. Occupational contact dermatitis in hairdressers/cosmetologists: retrospective analysis of North American Contact Dermatitis Group Data, 1994 to 2010. Dermatitis 2012; 23: 258-68.

42. Thyssen JP, Milting K, Bregnhøj A, et al. Nickel allergy in patchtested female hairdressers and assessment of nickel release from hairdressers' scissors and crochet hooks. Contact Dermatitis 2009; 61: 281-6.

43. Clemmensen OJ, Menné T, Kaaber K, Solgaard P. Exposure of nickel and the relevance of nickel sensitivity among hospital cleaners. Contact Dermatitis 1981; 7: 14-8.

44. Thyssen JP, Ross-Hansen K, Menné T, Johansen JD. Patch test reactivity to metal allergens following regulatory interventions: a 33-year retrospective study. Contact Dermatitis 2010; 63: 102-6.

45. European Parliament and Council Directive 94/27/EEC. Official Journal of the European Communities, 22-07-1994. no. L 188/1-2 (nickel).

46. Commission Directive 2004/96/EC of 27 September 2004 amending Council Directive 76/769/EEC as regards restrictions on the marketing and use of nickel for piercing post assemblies for the purpose of adapting its Annex I to technical progress.

47. Sainio EL, Jolanki R, Hakala E, Kanerva L. Metals and arsenic in eye shadows. Contact Dermatitis 2000; 42: 5-10.

48. Kang IJ, Lee MH. Quantification of para-phenylenediamine and heavy metals in henna dye. Contact Dermatitis 2006; 55: 26-9.

49. Bocca B, Forte G, Petrucci F, Cristaudo A. Levels of nickel and other potentially allergenic metals in Ni-tested commercial body creams. J Pharm Biomed Anal 2007; 44: 1197-202.

50. Liden C, Menne T, Burrows D. Nickel containing alloys and platings and their ability to cause dermatitis. Br I Dermal 1996; 134: 193-8.

51. Hemingway JD, Molokhia MM. The dissolution of metallic nickel in artificial sweat. Contact Dermatitis 1987; 16: 99-105.

52. Milosev I, Kosec T. Metal ion release and surface composition of the $\mathrm{CU}-18 \mathrm{Ni} 20 \mathrm{Zn}$ nickel silver during 30 days immersion in artificial sweat. Appl Surf Sci 2007; 254: 644-52.

53. Morgan JK. Observations on the persistence of skin sensitivity with reference to nickel eczema. Br J Dermatol 1953; 65: 84-94.

54. van Hoogstraten IMW, Andersen KE, Von Blomberg BME, et al. Reduced frequency of nickel allergy upon oral nickel contact at an early age. Clin Exp Immunol 1991; 85: 441-5. 